\title{
Editorial
}

\section{The Editor-in-Chief's parting words}

\author{
Colin Carlile \\ Department of Physics and Astronomy, Uppsala University, Uppsala, Sweden \\ E-mail: colin.carlile@gmail.com
}

\begin{abstract}
"It was the best of times, it was the worst of times" are the opening words of Charles Dickens' Tale of Two Cities. He was talking of Paris and London in the late 1700s before and during the French Revolution. We do not see a revolution facing neutron scattering but we do see both positive and negative trends. The current situation is, on the whole, very positive with improvements in instrumentation and new sources being built in Argentina and Lund. However, we do not see what we see in other disciplines such as astronomy or high-energy physics, which is a confidence that we must prepare, not just for tomorrow and the day after, but for the next generation of researchers who have just been born. For neutrons there is not the equivalent of the Overwhelmingly Large Telescope or the Future Circular Collider, ambitious projects, technically demanding and politically challenging, which are unlikely to begin construction for 30, 40 or 50 years. But for which designs exist.

The user base for neutrons appears to be content with what it has or what it will have in the foreseeable future and incremental change. Is that a reasonable position to take, or does it lack vision? Is it pragmatic and sensible, or does it demonstrate a limited ambition? I am firmly in the second camp. It cannot be described as fiddling while Rome burns but it has echoes of that. We, as a community, need to take the initiative, to get onto the front foot, to use a cricketing analogy. Yes, there is work going on exploring smaller sources using new techniques, but where is the conceptual thinking for the global source that will wear the mantle of the flagship neutron facility in the second half of this century? Is there even a mechanism to address this question?

It is against this background that Eddy Lelièvre-Berna takes over the editorship of the Journal of Neutron Research. I have decided that, after 14 years as editor following on from Gerry Lander, that it is a good moment to pass the torch to the next generation. JNR has a new livery under the wing of a new publisher, IOS Press, and the transition period of the past few years has been very positive. It is time now for new blood in the Editor' role and for increased momentum. I am confident that Eddy will bring that impetus and I wish him well in his task together with the Editorial Board. I am sure that you, the neutron community, will support him in this job. He has the right credentials and he has a broad view. And importantly he has the right personality. I thank IOS Press for their confidence in the journal. They are a niche publisher and JNR is a niche journal and that is an important aspect. Especially I should thank David Greaves and Kairi Look from IOS Press, each in their own different ways contributing to making JNR a success. Finally I thank you the readers and the contributors and I express my gratitude to my administrators, Patrizia Cuccari and Gill Carlile, who saw to it that the papers were processed in a systematic way.
\end{abstract}

